\title{
Foraging strategy of the asteroid Leptasterias polaris: role of prey odors, current and feeding status
}

\author{
Rémy Rochette, Jean-François Hamel, John H. Himmelman \\ Département de biologie et GIROQ (Groupe interuniversitaire de recherches océanographiques du Québec), \\ Université Laval, Ste-Foy, Québec, Canada G1K 7 P4
}

\begin{abstract}
We performed laboratory experiments to investigate the perception and localization of prey by the subtidal asteroid Leptasterias polaris. Motivation to eat greatly influences its responsiveness to current and waterborne odors from prey. Fed asteroids behave erratically, whereas asteroids starved for 2 mo exhibit predictable behaviors revealing the species' foraging strategy. In the absence of prey, starved asteroids search by moving cross-current which increases the probability of encountering odor plumes. In conditions of varying current velocities (differences of 0.5 to $1 \mathrm{~cm} \mathrm{~s}^{-1}$ ), movement is cross-stream towards the stronger current and 2- to 3 -fold faster in strong ( $\mathrm{ca} 17 \mathrm{~cm} \mathrm{~s}^{-1}$ ) than in weak (ca $0.7 \mathrm{~cm} \mathrm{~s}^{-1}$ ) current. We hypothesize that strong currents are preferred because they increase the spatial definition of odor plumes which facilitates localizing prey. When starved $L$. polaris perceive prey, they move upstream towards the odor plume. Because this should reduce the predator's conspicuousness, it may increase its chances of capturing the prey.
\end{abstract}

KEY WORDS: Foraging strategy $\cdot$ Asteroid $\cdot$ Leptasterias polaris $\cdot$ Olfaction $\cdot$ Current $\cdot$ Starvation

\section{INTRODUCTION}

Asteroids are major predators in marine ecosystems, and many aspects of their feeding biology have been studied (see reviews by Feder \& Christensen 1966, Sloan 1980a, Jangoux \& Lawrence 1982). However, the means by which they detect and localize food resources in nature are poorly understood. Potential mechanisms are chance encounters with prey (e.g. Mauzey et al. 1968, Feder 1970, Menge 1972, Dayton 1973, Dayton et al. 1977) and foraging based on the use of olfactory cues (e.g. Valentinčič 1973, Moitoza \& Phillips 1979, McClintock \& Lawrence 1981, McClintock et al. 1984). The ability of asteroids to detect prey from a distance may vary among species as Sloan \& Campbell (1982) report positive evidence of distance chemodetection (olfaction) for 14 species, negative evidence for 5 species, and contradictory evidence for 4 species. For species with an ability to detect waterborne odors, the capacity only appears to be functional over short distances (Feder \& Christensen 1966).
An animal which detects a prey or food material from waterborne odors may localize this resource by moving upstream in response to the mechanical stimulation of the current (rheotaxis), by moving up the odor concentration gradient (chemotaxis) (Atema 1985), or by a combination of both mechanisms. In all cases, localization of the prey will be most effective if current flow is sustained in one direction. Consequently, subtidal asteroids are more likely to use olfaction to detect and localize prey than asteroids from the more turbulent (wave-washed) intertidal zone (Sloan 1980a). Although there are numerous studies which examine the effect of current on the feeding behavior of subtidal animals, most focus on scavengers and suspension feeders, and few examine predators. The movement of scavenging amphipods, crabs, gastropods and fishes towards bait is strongly affected by current direction, velocity, and directional stability (e.g. Miller 1978, Thurston 1979 , Lampitt et al. 1983, Wilson \& Smith 1984, Himmelman 1988. McQuinn et al. 1988, Lapointe 1991), and the orientation of food-capturing organs of suspension 
feeders (crinoids, brittle-stars, and sea cucumbers) is adjusted to current conditions (e.g. Meyer 1973, Macurda \& Meyer 1974, Warner \& Woodley 1975, Woodley 1975, Ölscher \& Fedra 1977, LaBarbera 1978). Current conditions might also be expected to influence predators which rely on olfaction to detect and localize prey in subtidal habitats.

Since the diffusion of molecules in aquatic systems is highly dependent upon hydrodynamics (Atema 1988, Dodds 1990), foraging strategies of marine animals and their sensitivity to prey odors should be studied by examining behavioral responses to chemical and current stimuli simultaneously. Four such studies have been carried out on asteroids, three on Asterias rubens (Castilla \& Crisp 1970, 1973, Nickell \& Moore 1992) and one on Crossaster papposus (Sloan \& Northway 1982). All report upstream movement, in both the presence and the absence of prey odor, although in exceptionally fast current $\left(30 \mathrm{~cm} \mathrm{~s}^{-1}\right), A$. rubens moves downstream if prey odor is absent (Nickell \& Moore 1992). Castilla \& Crisp (1973) suggest that a positive rheotaxis under weak current conditions is the only effective manner of localizing a detected prey in habitats where odor gradients cannot be maintained. Though probably true, this would not account for the upstream movements of the above asteroids when prey odor is absent.

Leptasterias polaris is a major predator of subtidal communities in the St. Lawrence Estuary (Himmelman \& Lavergne 1985) and northern Gulf of St. Lawrence (Himmelman \& Dutil 1991), eastern Canada. Its feeding and population biology are described by Dutil (1988) and Himmelman \& Dutil (1991). Juveniles and small adults ( $<15 \mathrm{~cm}$ in diameter) are mostly found on rocky substrates in shallow water $(<8 \mathrm{~m}$ below lowest water of spring tides) where they feed on the small bivalves Mytilus edulis and Hyatella arctica. Large adults ( $>15$ to $20 \mathrm{~cm}$ in diameter) on the other hand occupy cobble to sand and mud areas at greater depths and feed on large infaunal bivalves (e.g. Serripes groenlandica, Spisula polynyma, Mya truncata, Ensis directus) and epibenthic gastropods (Buccinum undatum, Aporrhais occidentalis). It is not known whether prey items are encountered by chance or detected and localized at a distance. We investigated this question by examining the responses of $L$. polaris to current stimuli in the presence and absence of waterborne prey odors. Since preliminary tests indicated that the behavior of $L$. polaris varies markedly depending on its state of hunger, we quantify the responses of both starved and fed individuals.

\section{MATERIALS AND METHODS}

Experimental design. Thirty Leptasterias polaris, measuring 15 to $30 \mathrm{~cm}$ in diameter, were collected by
SCUBA divers in November and December 1991 from Anse aux Basques, near Les Escoumins $\left(48^{\circ} 32^{\prime} \mathrm{N}\right.$, $69^{\circ} 41^{\prime} \mathrm{W}$ ), on the north coast of the St. Lawrence Estuary, eastern Canada. They were divided into 2 groups of 15 individuals. Each group was kept in 4 plastic baskets $(45 \times 25 \mathrm{~cm})$ suspended in a $16000 \mathrm{l}$ holding tank which was maintained under constant conditions $\left(5^{\circ} \mathrm{C}, 30\right.$ to $32 \%$ salinity and $12 \mathrm{~h}$ light: $12 \mathrm{~h}$ dark). For 2 mo, the asteroids in one tank were fed blue mussels Mytilus edulis ad libitum. Those in the other tank were kept without food to increase their motivation to eat. Neither group showed signs of deteriorating condition after 2 mo. Individuals deprived of food displayed consistent and reproducible behaviors during the experiments, which suggested that they had not been adversely affected by the fasting (Sloan 1980a). Previous observations indicate that asteroids can tolerate long (> $3 \mathrm{mo}$ ) periods of starvation (Feder 1970, Valentinčič 1973, McClintock \& Lawrence 1984, author's unpubl. data on $L$. polaris). This is particularly likely for $L$. polaris because it is a cold-water species and because females routinely do not feed for $>4$ mo while brooding their young (Boivin et al, 1986).

We observed the behavior of Leptasterias polaris in a plexiglass aquarium $(125 \times 125 \times 14 \mathrm{~cm})$ which was uniformly lit by 2 fluorescent lights. The bottom was marked off in a grid $(5 \mathrm{~cm}$ squares; Fig. 1) to facilitate monitoring of the movements of the asteroids. A current was generated across the aquarium using 2 pumps which fed water into both ends of a $135 \mathrm{~cm}$ plexiglass tube. The tube was perforated by numerous holes and positioned along one side of the aquarium. Water passed across the aquarium and left through holes in the opposite wall. The water supplying the aquarium was from the large recirculating system of the Quebec Aquarium. We initially intended to compare the behavior of $L$. polaris under uniform and straight current crossing the aquarium (pumps on) to that under still conditions (pumps off). However, observations of the dispersion of drops of methylene blue released at $2 \mathrm{~cm}$ from the bottom at specific points in the system showed than when both pumps were on, current velocity was slightly greater to the right of the center of the aquarium (where the asteroid was placed) than to the left (Fig. 1, long arrows). Further, on both sides current direction was at a slight angle rather than directly across the system. When both pumps were turned off, current velocity fell rapidly but, a weak current, which was slightly greater on the left side and also at a slight angle, persisted for ca $10 \mathrm{~min}$ (Fig 1, short arrows). This current was generated by the head which had built up when the pumps were on. These 2 conditions will henceforth be referred to as strong and weak current regimes, respectively. That current velocity differed between both sides of the aquarium 


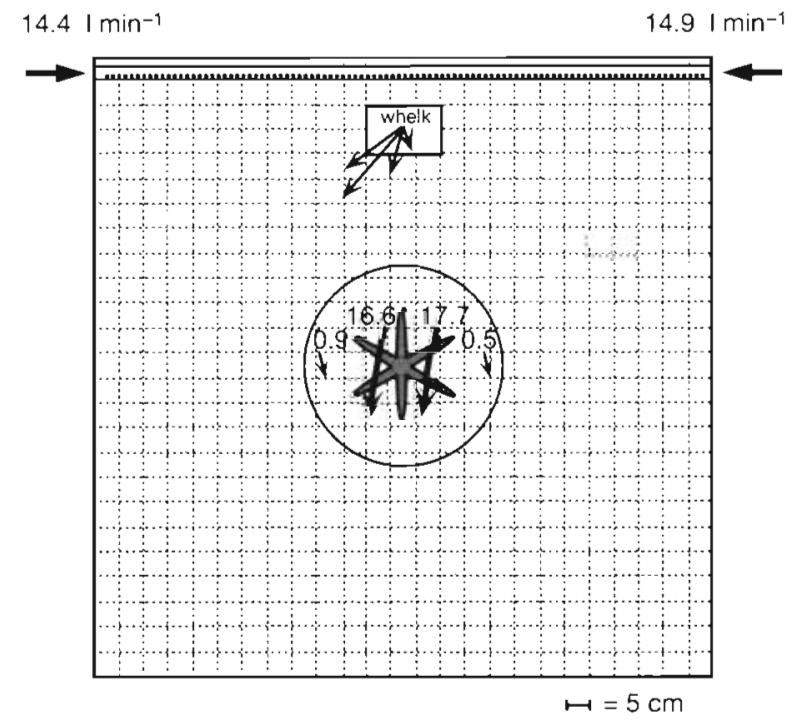

Fig. 1. Experimental aquarium showing position of asteroids at the beginning of each current regime and the circle indicating $20 \mathrm{~cm}$ from starting point, and position of the whelk in experiments with prey odor; arrows radiating out from the whelk indicate the direction of the odor plume in both strong and weak current. Current was generated by 2 pumps which delivered water through a plexiglass tube perforated with holes (top). Arrows and numbers near the asteroid indicate current direction and velocity $\left(\mathrm{cm} \mathrm{s}^{-1}\right)$ during strong

(long arrows) and weak (short arrows) current regimes

permitted us to evaluate the sensitivity of $L$. polaris to small differences in current velocity in both the strong and the weak current regimes.

In tests with prey odor, we placed a $1 \mathrm{~mm}$ mesh box containing a common whelk (Buccinum undatum L., 6 to $7 \mathrm{~cm}$ in shell length), one of the asteroid's preferred prey (Dutil 1988, Himmelman \& Dutil 1991), $45 \mathrm{~cm}$ upstream from the asteroid. Dye tests showed that the odor plume did not flow straight across the tank but rather veered to the left side both when the pumps were on (strong current) and when they were off (weak current) (Fig. 1).

The rate of locomotion and direction of movements were first quantified in the absence of whelk odor by subjecting each asteroid to a strong current (ca $17 \mathrm{~cm}$ $\mathrm{s}^{-1}$, pumps on), a weak current (ca $0.7 \mathrm{~cm} \mathrm{~s}^{-1}$, pumps off), and then a strong current again (ca $17 \mathrm{~cm} \mathrm{~s}^{-1}$, pumps on). For each test, we recorded the position of the asteroids at $5 \mathrm{~min}$ intervals for a maximum of $45 \mathrm{~min}$ or until they reached the wall of the aquarium. Just prior to the second and third current regimes, the asteroids were gently repositioned in the center of the aquarium with the aid of a plastic stick. The latter was used to prevent possible effects of hand sweat on their behavior, such as reported for asteroids by Zafiriou (1972). Each asteroid was returned to the holding tank for 5 to $10 \mathrm{~d}$ prior to repeating the above tests in the presence of whelk odor.
An additional experiment was conducted to determine whether Leptasterias polaris would change direction if suddenly exposed to whelk odor. A total of 5 starved and 5 fed asteroids were tested as they were moving roughly perpendicular to a strong current (ca $17 \mathrm{~cm} \mathrm{~s}^{-1}$ ). We tested individuals moving in the same direction to reduce possible variations in the quality of the chemical signal which they received. At $15 \mathrm{~s}$ intervals and for a period of $20 \mathrm{~min}, 5 \mathrm{ml}$ of water, from a $500 \mathrm{ml}$ beaker which had previously contained a living 6 to $7 \mathrm{~cm}$ whelk for $30 \mathrm{~min}$, was added at ca $35 \mathrm{~cm}$ upstream from the asteroid.

Statistical analysis. The direction in which each Leptasterias polaris moved was recorded as it crossed a circle defined by a $20 \mathrm{~cm}$ radius from the starting point (Fig. 1). Although we tested 15 asteroids in each current regime, in both the presence and the absence of whelk odor, in some instances fed individuals moved slowly and did not reach the $20 \mathrm{~cm}$ line within the 45 min observation period. These were eliminated when comparing the orientation of asteroids in the various tests. Rayleigh's tests (Batschelet 1981) were used to determine if there was directionality $\left(H_{1}\right)$ in the movement of the asteroids. The test is based on sample size and the statistic $r$, which is equal to the length of the mean vector. The statistic $r$ is calculated by applying trigonometric functions to the vectors representing the direction chosen by each individual in an experiment, and serves as a measure of concentration in unimodal samples.

A 20 min duration was generally used to calculate the average locomotory rate of the asteroids, since in about $90 \%$ of the instances they did not reach the side of the aquarium within this time. When they did, the locomotory rate was estimated from the distance covered in the first $15 \mathrm{~min}$. Locomotory rates were not always normally distributed so they were compared using nonparametric statistics. Friedman 2-way ANOVAs (Siegel 1956) were used to determine if the locomotory rates of starved and fed asteroids, in either the presence or the absence of prey odor, differed in the 3 successive current regimes. When significant differences were detected, locomotory rates in the first and second current regimes and then in the second and third current regimes were compared using Wilcoxon matched-pairs, signed-ranks tests (Siegel 1956).

\section{RESULTS}

\section{Response of starved asteroids}

Starved Leptasterias polaris always reached the line indicating $20 \mathrm{~cm}$ from the starting point within $20 \mathrm{~min}$, 
regardless of current speed and presence or absence of whelk odor. When a food source was upstream, asteroids displayed arm curling and terminal tube-foot responses, as previously reported for Crossaster papposus (Sloan 1980b) and Marthasterias glacialis (Valentinčič 1973). Furthermore, their movements were oriented $(p<0.05)$, not directly towards the whelk but towards its odors as indicated by the analysis of current

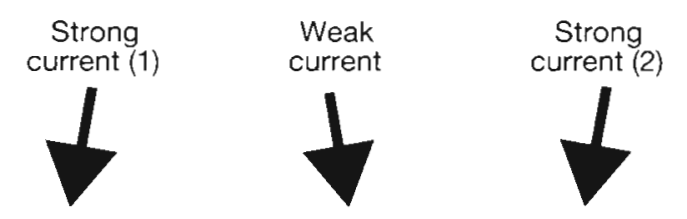

Starved Leptasterias polaris

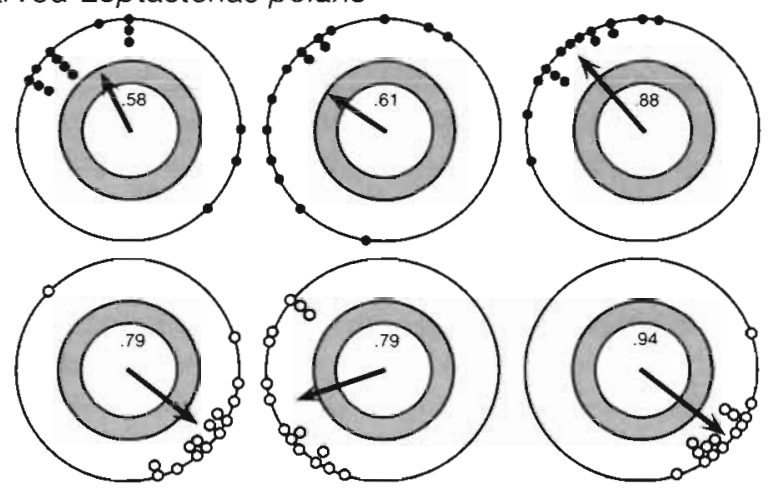

Fed Leptasterias polaris

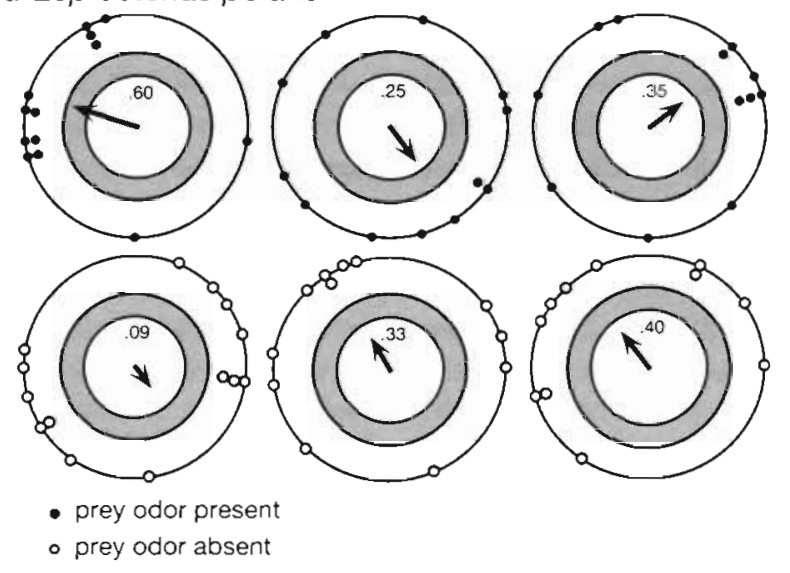

Fig. 2. Leptasterias polaris. Orientation of starved and fed asteroids during the first strong current regime, weak current regime and second strong current regime, in both the presence and the absence of prey odor. Arrows at the top of the figure indicate current direction in the center of the aquarium. Each point represents the orientation of 1 individual (points are stacked when 2 or more individuals have the same orientation). Arrows represent the mean vector, and numbers the $r$-values. Orientation is significant at the 0.05 level when the arrows reach the first concentric circle and at the 0.001 level when they reach the second circle (Rayleigh's tests) direction using methylene blue (Figs. 1 \& 2). In the absence of whelk odor, the movement of starved asteroids was still oriented $(p<0.001)$. As indicated earlier, current strength differed between the 2 sides of the experimental aquarium. Starved individuals consistently chose the side with the stronger current the right side in strong current and the left side in weak current) and they moved cross-current (Fig. 2). Their orientation was not precisely perpendicular to the current but rather slightly downstream. Thus, the angle was $>90^{\circ}$ for 35 of the 45 starved $L$. polaris tested in the 3 current conditions. Further, the $95 \%$ confidence interval about the average orientation angle included the $90^{\circ}$ orientation only when the current was weak $\left(118 \pm 22^{\circ}, 100 \pm 22^{\circ}\right.$ and $119 \pm 10^{\circ}$, for the first strong, weak and the second strong current regimes, respectively).

In both the presence and the absence of whelk odor, the locomotory rate of starved Leptasterias polaris varied markedly with current regime ( $p<0.001$; Fig. 3). It decreased sharply between the first strong current regime and the subsequent period of weak current ( $p<$ 0.001 ), and then increased 2 - to 3 -fold as strong current was reintroduced $(p<0.001)$.

\section{Response of fed asteroids}

The behavior of fed Leptasterias polaris differed strikingly from that of starved asteroids. Firstly, $18 \%$ of fed L. polaris did not reach the $20 \mathrm{~cm}$ radius circle within 45 min and several remained nearly stationary. Secondly, in all but 1 of the 6 tests fed $L$. polaris exhibited no specific orientation (Fig. 2). They were significantly oriented $(\mathrm{p}<0.05)$ only during the first strong current regime in the presence of whelk odor. When returned to the center of the aquarium at the beginning of each current regime, the asteroids were randomly oriented and may have continued moving in the direction in which we placed the previously 'leading arm'. This possibility was explored using 5 fed individuals. Each was allowed to move about in the aquarium in a strong current and on 3 occasions, when the asteroid was moving in a straight line, the orientation of its leading arm was changed by $90^{\circ}$ to $180^{\circ}$. The 5 asteroids consistently changed direction according to the new orientation of the 'leading arm'. In contrast, when 5 starved individuals were tested in the same manner, they consistently paused, during which time their terminal podia moved actively, and then resumed movement in the original direction relative to current flow. Thus, fed asteroids appeared to have a weak interest in feeding and their lack of orientation during the second and third current regimes was probably a result of the manipulations. 


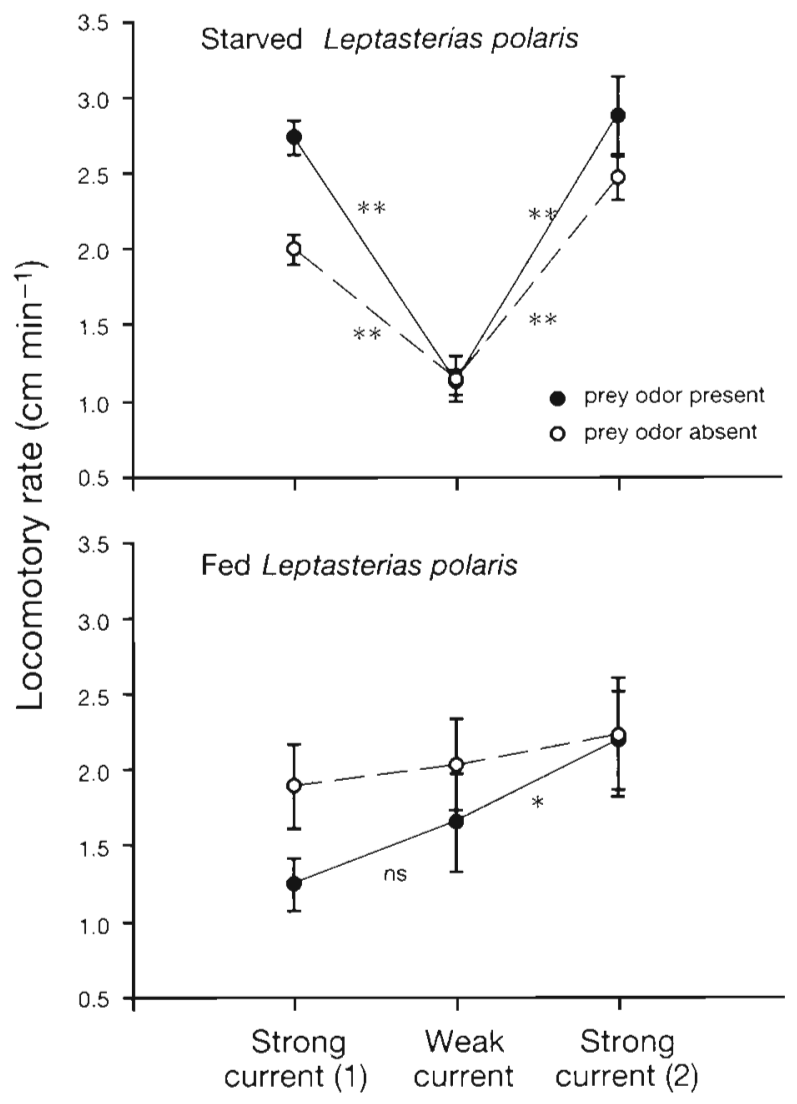

Fig. 3. Leptasterias polaris. Mean locomotory rates $\left(\mathrm{cm} \mathrm{min}^{-1}\right)$ of 15 starved and 15 fed asteroids during the first strong current regime, the weak current regime and the second strong current regime, in both the presence and the absence of prey odor. Vertical bars represent standard errors. Locomotory rates in 3 successive current regimes were compared using Friedman 2-way ANOVAs. When significant differences were detected $(p<0.05)$, locomotory rates in successive current regimes were compared by Wilcoxon matched-pairs signedranks tests. ns: not significant; ${ }^{*} p<0.05 ;{ }^{* *} p<0.001$

Locomotory rates of fed Leptasterias polaris differed significantly among the 3 current regimes only when prey odor was present (Fig. 3). Further, rates did not vary in a consistent manner with current velocity, rather, they tended to increase progressively through the 3 successive current regimes, in both the presence and the absence of whelk odor.

\section{Olfactory stimulation of moving asteroids}

In the tests where drops of water containing whelk odor were added upstream of starved Leptasterias polaris which were moving cross-current, all asteroids modified their trajectory and moved upstream. In contrast, all fed asteroids tested in the same manner did not modify their movements.

\section{DISCUSSION}

We show that the response of Leptasterias polaris to prey odors and current is strong and predictable for starved individuals but weak and variable for fed individuals. One explanation for the weak response of fed asteroids to whelk odor could be their exclusive consumption of mussels prior to the experiments (ingestive conditioning). However, the random movements of fed $L$. polaris when prey odors were absent suggest a general disinterest in feeding, likely the result of having been supplied with an excess of food for 2 mo prior to the experiments. This is supported by the observation that if their orientation is changed, fed individuals continue moving in the direction of the previously 'leading arm', whereas starved individuals reorient themselves relative to current flow. The way in which animals react to external stimuli is highly variable and often related to physiological condition (Schöne 1984, p. 57-58). An increased responsiveness to prey odors with increasing hunger may generally be true for asteroids since it has been reported for a number of other species (e.g. Brauer \& Jordan 1970 , Valentinčič 1973, 1975, Ribi \& Jost 1978, McClintock \& Lawrence 1984). Failure to take this factor into account might partly explain the controversy concerning olfactory capacities of asteroids.

\section{Foraging strategy of Leptasterias polaris}

Leptasterias polaris which are motivated to eat detect their prey from waterborne odors and their rate of movement, in both the presence and the absence of prey odors, is highly dependent upon current conditions. This supports the hypothesis that olfaction is used in detecting and localizing prey. The long terminal tube feet of asteroids are responsible for the detection of odors (Sloan 1980b) and the fact that those on several arms are active at the same time possibly provides the spatial and temporal resolution required for detecting and defining the structure of odor plumes. This type of sampling of the water may thus be analogous to 'sniffing' by fishes, 'antennular flicking' by lobsters, and 'swinging of the siphon' by gastropods (Atema 1985).

Animals which rely on odors to detect food may either wait or actively search for these odors. In the latter case, food intake must be increased to compensate for the additional energy invested into locomotion (Norberg 1977). Hughes (1980) points out that searching for prey will become a less advantageous strategy as their density decreases, because of the increased locomotory costs. Active search is probably advantageous for Leptasterias polaris as its prey are relatively 
abundant and also because most of them are not mobile. Three aspects of its behavior in relation to current conditions may increase foraging success: (1) cross-stream movements which increase the chance of detecting prey odors, (2) a preference for strong currents which enhances localizing a prey once detected and (3) approaching prey from downstream which renders the asteroid less conspicuous to its prey.

\section{Cross-current movement}

In both strong and weak current, hungry Leptasterias polaris search for prey by moving cross-stream. At spatial and temporal scales pertinent to this predator, the dispersion of odor molecules depends mainly on the dynamics of the carrier medium and substrate topography and is little affected by diffusive processes at the molecular level (Okubo 1980, Atema 1988). Patchy odor plumes, which form downstream from foodstuffs (Lam et al. 1983, Atema 1988, Denny 1988), will most likely be encountered if animals move crossstream. The slightly downstream orientation indicated by our data, if not an artifact caused by nonuniform current flow throughout the aquarium, might be an adaptation to minimizing turbulence around the tube feet. This would facilitate determining from where prey odors originate.

Our study is the first documentation of a crossstream search path for an asteroid. However, crossstream movements have been observed for the whelk Buccinum undatum (Sainte-Marie 1991). An analogous situation is the movement of insects flying to locate mate, host or prey odors. Cross-wind movement is considered to be optimal (Bell \& Cardé 1984) but has not been clearly demonstrated by field studies. This may be due to the lack of studies simultaneously evaluating wind direction and the path of the insect (Murlis et al. 1992). Nevertheless, flying insects have been shown to fly across the wind when they momentarily lose odor plumes (David 1986).

\section{Preference for increased current velocity}

The search strategy of Leptasterias polaris appears to be finely tuned to current velocity. Thus, $L$. polaris detects even small differences in current velocity (differences as little as 0.5 to $1 \mathrm{~cm} \mathrm{~s}^{-1}$ ), moves cross-stream in the direction of the stronger current and increases it's locomotory rate by 2 - to 3 -fold in strong current. Turbulent diffusion and thermal agitation cause molecules to wander about the main stream direction of the current and the average distance of departure from this axis increases moving downstream (Denny 1988).
This can be visualized as a general widening of the odor plume in the downstream direction. An increase in current velocity decreases the width of the odor plume by limiting the drift of molecules from the main stream direction (Okubo 1980, Denny 1988). Consequently, stronger currents will generally increase the spatial definition of odor gradients and this enhances the capacity of animals to locate food materials perceived from exuded chemicals (Kleerekopper et al. 1975).

Although identifying the origin of an odor plume may be easier in strong current, the ability of animals to encounter prey or food materials using olfaction is probably not always enhanced by strong currents. Since decreased current velocity increases the width and thus the area of the odor plume, it also increases the number of individuals which are in a position to detect it. This is supported by field studies of McQuinn et al. (1988) which show that the effective area fished by a baited whelk trap is greater in weak $\left(10 \mathrm{~cm} \mathrm{~s}^{-1}\right)$ than in strong $\left(26 \mathrm{~cm} \mathrm{~s}^{-1}\right)$ current. A recent study by Lapointe \& Sainte-Marie (1992) suggests that both strong and weak currents may enhance the localization of bait by scavenging whelks. They observed that the rate at which whelks arrived at bait is positively correlated to current velocities prevailing 0.5 to $3 \mathrm{~h}$ prior to their arrival but tends to be negatively correlated for longer time lags. Since short time lags presumably reflect interactions which occur in the vicinity of the bait and longer time lags those occurring further away, it appears that strong currents may aid nearby whelks in localizing bait, whereas weak currents may increase the number of whelks detecting bait from further away. This does not imply that whelks are attracted from greater distances when currents are weak, only that the area from which they are attracted is greater because weak currents increase the width of odor plumes.

Whether weak or strong currents increase the foraging efficiency of marine animals probably depends upon factors such as the availability of food materials and the consumer's chemosensory and locomotory abilities. Scavengers exploit rare and often distant sources of food and this explains why scavenging fishes, amphipods and gastropods often possess well-developed olfactory and locomotory abilities. These permit them to detect and localize food over distances from tens of meters to kilometers (Sainte-Marie \& Hargrave 1987, Himmelman 1988, Lapointe \& Sainte-Marie 1992). Since their intake of prey depends upon their ability to detect such food materials, weak currents, which spread odors over a wide area, may be advantageous. On the other hand, asteroids generally exploit prey which are abundant and can be obtained over a distance of a few meters. Further, their chemosensory and locomotory abilities 
are weak. Whereas the area covered by an odor plume may have little importance in determining prey intake for asteroids, strong current may be critical, because it enhances the ability to localize prey.

\section{Approaching prey from downstream}

We studied how Leptasterias polaris detects and lacates epibenthic prey such as the whelk Buccinum undatum. Similar mechanisms may be employed in the search and capture of clams and other endobenthic prey. Adult L. polaris frequently feed on large bivalves which they extract from the sediments using their podia, in a manner similar to that described by Smith (1961) for Pisaster brevispinus. As suggested by Smith, it is likely that infaunal prey are detected prior to digging to prevent useless expenditures of energy. However, whelks and endobenthic bivalves also use waterborne odors to detect their predators and they possess defensive mechanisms to decrease the probability of being captured: whelks flee from L. polaris and bivalves bury themselves so that they are less readily found and captured (Legault \& Himmelman 1993). Irrespective of the type of prey being consumed, L. polaris likely increases its feeding efficiency by approaching prey from a downstream direction, since this should make its presence less apparent and could permit taking the prey by surprise, particularly under conditions of regular and rapid current flow.

Our laboratory studies indicate that the detection of waterborne prey odors is a key element in the foraging strategy of Leptasterias polaris. Further investigations, and especially field studies, are required to elucidate how prey are detected and localized in natural habitats where current conditions are highly variable, where prey are abundant and frequently patchily distributed, and where the energy requirements of $L$. polaris vary among individuals and over time.

Acknowledgements. We are grateful to the Quebec Aquarium for providing the reliable laboratory facilities which made these observations possible, to B. Sainte-Marie and J. N. McNeil for numerous suggestions which improved the text and to L. Pageau who aided in collecting the asteroids. The project was financially supported by NSERC and FCAR grants to J.H.H.

\section{LITERATURE CITED}

Atema, J. (1985). Chemoreception in the sea: adaptations of chemoreceptors and behavior to aquatic stimulus condjtions. Symp. Soc. exp. Biol. 39: 387-423

Atema, J. (1988). Distribution of chemical stimuli. In: Atema, J., Fay, R. R., Popper, A. N., Tavolga, W. N. (eds.) Sensory biology of aquatic animals. Springer-Verlag, New York, p. $29-56$
Batschelet, E. (1981). Circular statistics in biology. Academic Press, Inc., New York

Bell, W. J., Cardé, R. T. (1984). Chemical ecology of insects. Chapman \& Hall, New York

Boivin, Y., Larrivée, D., Himmelman, J. H. (1986). Reproductive cycle of the subarctic brooding asteroid Leptasterias polaris. Mar. Biol. 92: 329-337

Brauer, R. W., Jordan, M. R. (1970). Triggering of the stomach eversion reflex of Acanthaster planci by coral extracts. Nature 228: $344-346$

Castilla, J. C., Crisp, D. J. (1970). Responses of Asterias rubens to olfactory stimuli. J. mar. biol. Ass. U.K. 50: 829-847

Castilla, J. C., Crisp, D. J. (1973). Responses of Asterias rubens to water currents and their modification by certain environmental factors. Neth. J. Sea Res. 7: 171-190

David, C. T. (1986). Mechanisms of directional flight in wind. In: Payne, T. L., Birch, M. C., Kennedy, C. E. J. (eds.) Mechanisms in insect olfaction. Oxford University Press, New York, p. 49-57

Dayton, P. K. (1973). Two cases of resource partitioning in an intertidal community: making the right prediction for the wrong reason. Am. Nat. 107: 662-670

Dayton, P. K., Rosenthal, R. J., Mahen, L. C., Antezana, T (1977). Population structure and foraging biology of the predaceous Chilean asteroid Meyenaster gelatinosus and the escape biology of its prey. Mar. Biol. 39: 361-371

Denny, M. W. (1988). Biology and the mechanics of the waveswept environment. Princeton University Press, Princeton

Dodds, W. K. (1990). Hydrodynamic constraints on evolution of chemically mediated interactions between aquatic organisms in unidirectional flows. J. chem. Ecol 16: $1417-1430$

Dutil, C. (1988). Partage des ressources alimentaires et comportement de prédation des étoiles de mer de la communauté infralittorale du golfe du Saint-Laurent. M.Sc. thesis, Université Laval, Ste-Foy

Feder, H. M. (1970). Growth and predation by the ochre sea star, Pisaster ochraceus (Brandt), in Monterey Bay, California. Ophelia 8: 161-185

Feder, H. M., Christensen, A. M. (1966). Aspects of asteroid biology. In: Boolootian, R. A. (ed.) Physiology of Echinodermata. Interscience, New York, p. 87-127

Himmelman, J. H. (1988). Movement of whelks (Buccinum undatum) towards a baited trap. Mar. Biol. 97: 521-531

Himmelman, J. H., Dutil, C. (1991). Distribution, population structure and feeding of subtidal seastars in the northern Gulf of St. Lawrence. Mar. Ecol. Prog. Ser 76: 61-72

Himmelman, J. H., Lavergne, Y. (1985). Organization of rocky subtidal communities in the St. Lawrence Estuary. Nat. can. 112: 143-154

Hughes, R. N. (1980). Optimal foraging theory in the marine context. Oceanogr. mar. Biol. A. Rev. 18: 423-481

Jangoux, M., Lawrence, J. M. (1982). Echinoderm nutrition. A. A. Balkema, Rotterdam

Kleerekopper, H., Gruber, D., Matis, J. (1975). Accuracy of localization of a chemical stimulus in flowing and stagnant water by the nurse shark, Ginglymostoma cirratum. J. comp. Physiol. 98: 257-275

LaBarbera, M. (1978). Particle capture by a specific brittle star: experimental test of the aerosol suspension feeding model. Science 201: 1147-1149

Lam, D. C. L., Murthy, C. R., Simpson, R. B. (1983). Effluent transport and diffusion models for the coastal zone. Springer-Verlag, New York

Lampitt, R. S., Merret, N. R., Thurston, M. H. (1983). Interrelations of necrophagous amphipods, a fish predator, and tidal currents in the deep sea. Mar. Biol. 74: 73-78 
Lapointe, V (1991). Effets du courant et de la présence d'espèces compétitrices ou prédatrices sur l'arrivée à l'appât du buccin commun, Buccinum undatum (Linné). M.Sc. thesis, Université du Québec à Rimouski

Lapointe, V., Sainte-Marie, B. (1992). Currents, predators, and the aggregation of the gastropod Buccinum undatum around bait. Mar. Ecol. Prog. Ser. 85: 245-257

Legault, C., Himmelman, J. H. (1993). Relation between escape behaviour of benthic marine invertebrates and the risk of predation. J. exp. mar. Biol. Ecol. 170: 55-74

Macurda, D. B., Meyer, D. L. (1974). Feeding posture of modern stalked crinoids. Nature 247: 394-396

Mauzey, K. P., Birkeland, C., Dayton, P. K. (1968). Feeding behavior of asteroids and escape responses of their prey in the Puget Sound region. Ecology 49: 603-619

McClintock, J. B., Klinger, T. S., Lawrence, J. M. (1984). Chemoreception in Luidia clathrata (Echinodermata: Asteroidea): qualitative and quantitative aspects of chemotactic responses to low molecular weight compounds. Mar. Biol. 84: 47-52

McClintock, J. B., Lawrence, J. M. (1981). An optimization study on the feeding behavior of Luidia clathrata Say (Echinodermata: Asteroidea). Mar. Behay. Physiol. 7 . 263-275

McClintock, J. B., Lawrence, J. M. (1984). Ingestive conditioning in Luidia clathrata (Say) (Echinodermata: Asteroidea): effect of nutritional condition on selectivity, teloreception, and rates of ingestion. Mar. Behav. Physiol. 10: $167-181$

McQuinn, I. H., Gendron, L., Himmelman, J. H. (1988). Area of attraction and effective area fished by a whelk (Buccinum undatum trap under variable conditions. Can. J. Fish. Aquat. Sci. 45: 2054-2060

Menge, B. A. (1972). Foraging strategy of a starfish in relation to actual prey availability and environmental predictability. Ecol. Monogr. 42: 26-50

Meyer, D. L. (1973). Feeding behavior and ecology of shallowwater stalked crinoids (Echinodermata) in the Caribbean Sea. Mar. Biol. 22: 105-129

Miller, R. J. (1978). Entry of Cancer productus to baited traps J. Cons. int. Explor. Mer 38: 220-225

Moitoza, D. J., Phillips, D. W. (1979). Prey defense, predator preference, and nonrandom diet: the interactions between Pycnopodia helianthoides and two species of sea urchins. Mar. Biol. 53: 299-304

Murlis, J., Elkinton, J. S., Cardé, R. T (1992). Odour plumes and how insects use them. A. Rev. Entomol. 37: 505-532

Nickell, T D., Moore, P. G. (1992). The behavioral ecology of epibenthic scavenging invertebrates in the Clyde Sea area: laboratory experiments on attractions to bait in moving water, underwater TV observations in situ and general conclusions. J. exp. mar. Biol. Ecol. 159: 15-35

Norberg, R. A. (1977). An ecological theory on foraging time and energetics and choice of optimal food-searching method. J. Anim. Ecol. 46: 511-529
Okubo, A. (1980). Diffusion and ecological problems: mathematical models. Springer-Verlag, New York

Ölscher, E. M., Fedra, K. (1977). On the ecology of a suspension feeding benthic community: filter efficiency and behavior. In: Keegan, B. F., Ceidigh, P. O., Boaden, P. J. S. (eds.) Biology of benthic organisms. Pergamon Press, Oxford, p. 483-492

Ribi, G., Jost, P. (1978). Feeding rate and duration of daily activity of Astropecten aranciacus (Echinodermata: Asteroidea) in relation to prey density. Mar. Biol. 45: 249-254

Sainte-Marie, B. (1991). Whelk (Buccinum undatum) movements and its implications for the use of tag-recapture methods for the determination of baited trap fishing parameters. Can. J. Fish. Aquat. Sci. 48: 751-756

Sainte-Marie, B., Hargrave, B. T. (1987). Estimation of scavenger abundance and distance of attraction to bait. Mar. Biol. 94: 431-443

Schöne, H. (1984). Spatial orientation. Princeton University Press, Princeton

Siegel, S. (1956). Nonparametric statistics for the behavioral sciences. McGraw-Hill, New York

Sloan, N. A. (1980a). Aspects of the feeding biology of asteroids. Oceanogr. mar. Biol. A. Rev. 18: 57-124

Sloan, N. A. (1980b). The arm curling and terminal tube-foot responses of the asteroid Crossaster papposus (L.). J. nat. Hist. 14: $469-482$

Sloan, N. A., Campbell, A. C. (1982). Perception of food. In: Jangoux, M., Lawrence, J. M. (eds.) Echinoderm nutrition. A. A. Balkema, Rotterdam, p. 3-23

Sloan, N. A., Northway, S. M. (1982). Chemoreception by the asteroid Crossaster papposus (L.). J. exp. mar. Biol. Ecol. 61: 85-98

Smith, L. S. (1961). Clam-digging behavior in the starfish, Pisaster brevispinus (Stimpson 1857). Behaviour 18: 148-153

Thurston, M. H. (1979). Scavenging abyssal amphipods from the north-east Atlantic Ocean. Mar. Biol. 51: 55-68

Valentinčič, T. (1973). Food finding and stimuli to feeding in the sea star Marthasterias glacialis. Neth. J. Sea Res. 7: 191-199

Valentinčič, T. (1975). Amino-acid chemoreception and other releasing factors in the feeding response of the sea star, Marthasterias glacialis (L.). In: Barnes, $H$. (ed.) Proc. 9th Eur. Mar. Biol. Symp. Univ. Aberdeen Press, Aberdeen, p. 693-705

Warner, G. F., Woodley, J. D. (1975). Suspension-feeding in the brittle-star Ophiothrix fragilis. J. mar. biol. Ass. U.K. 55: $199-210$

Wilson, R. R. Jr, Smith, K. L. Jr (1984). Effect of near bottom currents on detection of bait by the abyssal grenadier fishes Coryphaenoides spp., recorded in situ with a video camera on a free vehicle. Mar. Biol. 84: 83-91

Woodley, J. D. (1975). The behaviour of some amphiurid brittle-stars. J. exp. mar. Biol. Ecol. 18: 29-46

Zafiriou, O. (1972). Response of Asterias vulgaris to chemical stimuli. Mar. Biol. 17: 100-107

Manuscript first received: July 19, 1993

Revised version accepted: December 8, 1993 